\title{
Genetic relatedness between Ardi, Black Bedouin and Damascus goat breeds
}

\author{
R.M. Al-Atiyat ${ }^{1,2}$ and R.S. Aljumaah ${ }^{1}$ \\ ${ }^{1}$ Animal Production Department, King Saud University, Riyadh \\ Kingdom of Saudi Arabia \\ ${ }^{2}$ On Sabbatical Leave from Animal Production Department, \\ Mutah University, Karak, Jordan \\ Corresponding author: R.M. Al-Atiyat \\ E-mail: ralatiyat@ksu.edu.sa / raedatiyat@gmail.com
}

Genet. Mol. Res. 13 (2): 4654-4665 (2014)

Received June 17, 2013

Accepted January 13, 2014

Published June 18, 2014

DOI http://dx.doi.org/10.4238/2014.June.18.8

\begin{abstract}
The present study aimed to analyze genetic relatedness and differentiation of common native goat populations in some countries of the Middle East. The populations were Ardi, Black Bedouin, and Damascus goats in the Kingdom of Saudi Arabia, Jordan, and Syria, respectively. Domesticated goats of the Middle East are mostly related to common ancestors, but there is limited molecular genetic evidence. Four microsatellite DNA markers were genotyped in 89 individuals of the three populations using an automated genetic analyzer. Ardi, Black Bedouin, and Damascus goats exhibited high average allele number and expected heterozygosity of $8.25,9$, and 7.25 , and $0.750,0.804$, and 0.779 , respectively. $F$-statistics for population differentiation showed $6.0 \%$ of total genetic variation, whereas $94.0 \%$ as differentiation between individuals within all populations. The least varied within populations was Ardi goats, then Damascus goats and finally Black Bedouin goats. Furthermore, the Damascus goat population was more differentiated from Black Bedouin goats than from Ardi goats. On the other hand, there was strong evidence of admixture between the majority of Ardi and Black Bedouin goat individuals but little with those of Damascus
\end{abstract}


goats. Genetic distance between Ardi and Black Bedouin goats was the shortest, whereas it was the longest between Ardi and Damascus goats. The phylogenetic tree clearly revealed the expected degree of differentiation in the three populations. From a genetic conservation point of view, it is recommended to maintain the biodiversity of these distinct populations in case genetic migration of genetic resources and genetic conservation are absent.

Key words: Goat; Microsatellite marker; Genetic structure; Phylogeny

\section{INTRODUCTION}

Goats have historically been assigned to countries of the Arabian Peninsula and Middle East (Zeuner 1963; Mason, 1984). These countries have shown harsh tropical environmental conditions, where goats, in particular, express great adaptability (Galal, 2005). Furthermore, there is general and common agreement that domesticated animals descended from a single ancestor, originating in Asia. It is also reported that all world's breeds originated from central Asia since the Stone age (Devendra and McLeroy, 1987). In fact, the first domesticated goat (Capra hircus) was in the Fertile Crescent of the Middle East countries some 10,000-11,000 years ago (Zeuner, 1963; Mason, 1984; Zeder and Hesse, 2000; Pereira et al., 2009). At present time, the native goat breeds of most Arab countries are expected to be closely related to each other on the basis of morphological studies. For example, the most common native breed in the Kingdom of Saudi Arabia (KSA) is the Ardi goat (Alamer, 2006), which is historically assigned to Arabian deserts and is a plausible descendant of the Hejaz goat (Epstein, 1946). A similarly looking breed is the most common goat breed in Jordan, which is the Black Bedouin (Al-Tamimi, 2005), also known as Dihawi (Zaitoun et al., 2005). On the other hand, the most known goat breed in Syria is the Damascus goat, known sometimes as Shami. In other nearby countries, the common native goat breed is the Black Bedouin in Palestine (Silanikove, 1986) and Egyptian Baladi or Bedouin goat in Egypt (Agha et al., 2008).

The subtropical conditions of Arab countries challenge goats to better adapt and survive under environmental stresses of mainly recent heat stress and drought in intensive and extensive management systems (Al-Tamimi et al., 2013). In general, there is evidence that goat breeds of tropical areas have a range of unique genetic resources of adaptive traits (e.g., heat resistance, and water, feed and disease tolerance), which enable them to survive and produce in these conditions (Devendra and McLeroy, 1987; Ajmone-Marsan, 2010). As a consequence, they have low genetic potential for better production when compared to other indigenous and exotic goat breeds (Tabbaa and Al-Atiyat, 2009). However, goat breeds have recently faced major threats to their genetic diversity, which has resulted from systemic drought and unplanned crossbreeding with other native or exotic goats. Limited information is available on the molecular genetic diversity structure and relatedness of goats in Arab countries (Galal, 2005). Even though it is widely accepted that domesticated goats of this region are the most closely related to their common ancestors (Piper and Ruvinsky, 1997), there is no published reports stating so using molecular DNA markers. Microsatellite DNA markers in particular have provided wide opportunities to analyze biodiversity and genetic relationship between and within world goat breeds (Karaca et al., 
1999). They are also able to provide data on goat breeds' evolutionary relationships and phylogeny. The aim of this study was to report, presumably for the first time, on the genetic diversity, phylogeny and evolutionary analysis of most native goat breeds in KSA, Jordan, and Syria on the basis of microsatellite DNA markers.

\section{MATERIAL AND METHODS}

\section{Goat breeds}

The goat individuals included 30 Ardi, 37 Black Bedouin and 22 Damascus. All individuals were sampled from their country of origin, Ardi from KSA, Black Bedouin from Jordan and Damascus from Syria (Figure 1). They were unrelated kids from geographically separated herds in each country.

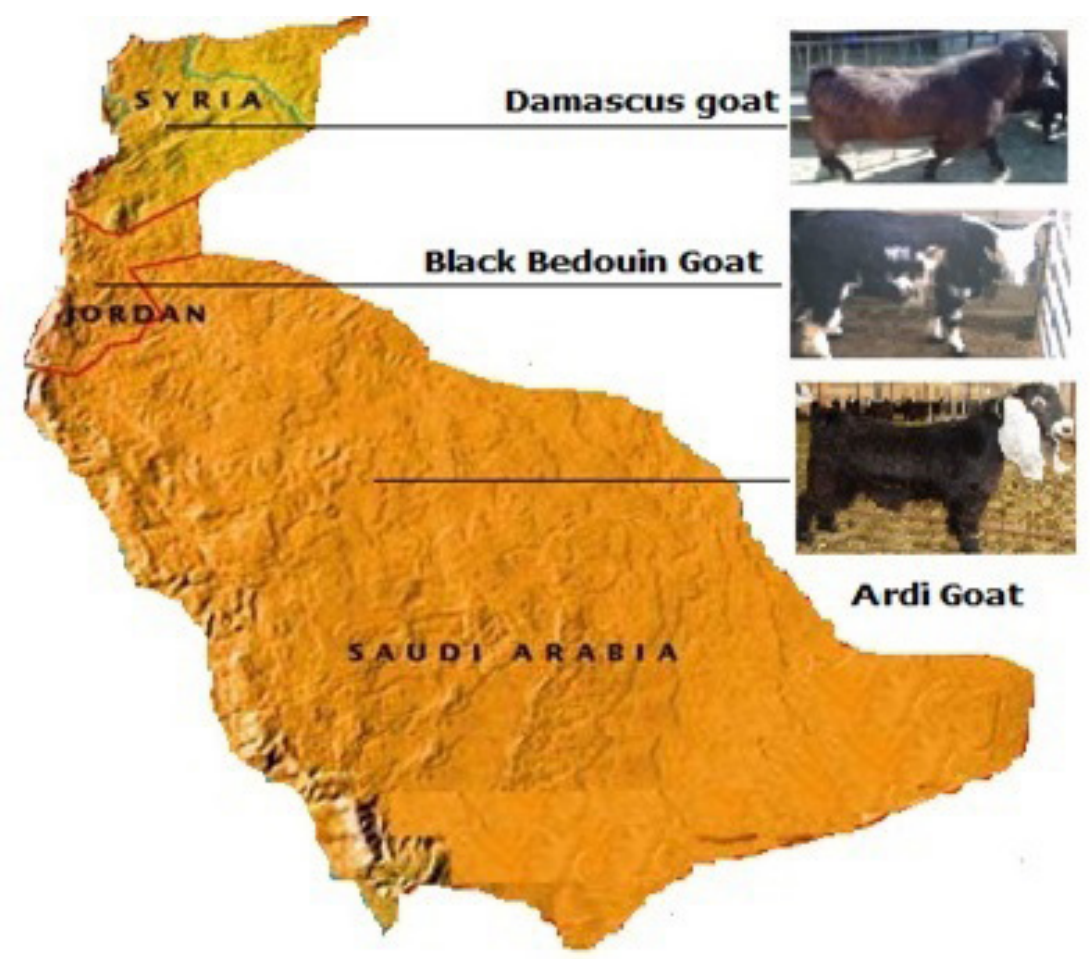

Figure 1. Geographical location of the three goat populations studied in the three countries.

\section{DNA extraction and quantification}

DNA was extracted using E.Z.N.A ${ }^{\circledR}$ MicroElute Genomic DNA extraction kit (OMEGA Bio-Tek, 2010). DNA concentrations were then determined using a Nano-DNA spectrophotometer (Alpha Innotech Corp. ${ }^{\circledR}, 2010$ ) considering the $\mathrm{A}_{260} / \mathrm{A}_{280}$ absorbance ratio. The DNA concentration was adjusted to $10 \mathrm{ng} / \mu \mathrm{L}$ for DNA genotyping. 


\section{DNA genotyping}

Four microsatellite DNA markers of ovine and bovine origin, CSRD247, OARAE54, ILSTS005, and McM527, were used for genotyping using a polymerase chain reaction (PCR) apparatus. The primer sequences and PCR requirements and details were taken from the FAO recommended list (FAO, 2011). PCR was carried out in a $10-\mu \mathrm{L}$ volume of DNA and master mix for genotyping the DNA samples. Thermal cycling was performed on a GeneAmp ${ }^{\circledR}$ PCR system 9700 (Applied Biosystem, USA). The amplified PCR products were separated using a 3130 Genetic Analyzer (Applied Biosystem). The size of the microsatellite alleles was determined and the data exported to Excel spreadsheets using the Gene Mapper Software (Version 3.0, Applied Biosystem). The microsatellite alleles in the Excel files were made into a specific format file to be analyzed by ARLEQUIN (ver 3.11) (Excoffier and Lischer, 2010).

\section{Analyses of genetic structure, differentiation and distances}

The hierarchical genetic structure of the samples and analysis of molecular variance (AMOVA), $F$-statistics and pairwise difference $\left(F_{\mathrm{ST}}\right)$ were computed using ARLEQUIN. The analyses included average number of alleles, gene diversity, standard diversity indices and intrapopulation differentiation level methods. The analysis of gene diversity was based on expected heterozygosity $\left(H_{\mathrm{E}}\right)$ for diploid data at each locus under Hardy-Weinberg equilibrium (HWE) (Nei, 1987). Furthermore, the Garza-Williamson $(G-W)$ index was used for measuring population bottleneck at the loci studied (Garza and Williamson, 2001). The population structure was analyzed using the STRUCTURE software (Pritchard et al., 2000) considering an admixture model and correlated allele frequencies between the populations studied. The lengths of the burn-in Monte Carlo Markov chain were 1000 and 10,000 in 100 runs for possible number of clusters $(\mathrm{K})$ from 2 to 6 . For each $\mathrm{K}$ value, log probability of data $(\mathrm{L}[\mathrm{K}])$ and $F_{\mathrm{ST}}$ values for each cluster were estimated. On the other hand, a genetic distance matrix between the three breeds was constructed on the basis of Nei's genetic distance estimates (Nei, 1987). Using the genetic distance matrix, the neighbor-joining and UPGMA phylogenetic tree was drawn using the MEGA program, version 5 (Tamura et al., 2011).

\section{RESULTS AND DISCUSSION}

\section{Genetic variation within breeds}

The total number of alleles and allele frequencies for each locus in each population are presented in Table 1. The highest number of alleles among the polymorphic markers was for OARAE54 in both Ardi (11) and Black Bedouin (12) and for CSRD247 in Damascus goat (9). Locus ILSTS005 exhibited the smallest number of alleles (5) in the three populations. The average number of alleles varied: 8.25 in Ardi, 9 in Black Bedouin and 7.25 in Damascus goats. These results show that the Damascus goat is less diverse than the other two goat populations. The overall mean of allele number for the loci studied in all populations was 8.17 (Table 1). These results indicate a reasonably high number of microsatellite alleles in the populations studied. Similar results were reported by independent studies on goats using different microsatellite markers (Bolormaa et al., 2008; Dixit et al., 2009; Aljumaah et al., 2012). 
Table 1. Genetic variation measures within each studied goat population at the four loci.

\begin{tabular}{|c|c|c|c|c|c|}
\hline \multirow[t]{2}{*}{ Locus name } & Allele number & $H_{\mathrm{O}}$ & $H_{\mathrm{E}}$ & Allele size range & G-W \\
\hline & \multicolumn{5}{|c|}{ Ardi } \\
\hline CSRD247 & 7 & 0.667 & 0.740 & 24 & 0.280 \\
\hline OARAE54 & 11 & 0.767 & 0.848 & 22 & 0.478 \\
\hline ILSTSO05 & 5 & 0.700 & 0.588 & 12 & 0.385 \\
\hline McM527 & 10 & 0.767 & 0.825 & 20 & 0.476 \\
\hline \multirow[t]{2}{*}{ Mean } & 8.25 & 0.725 & 0.750 & 19.5 & 0.405 \\
\hline & \multicolumn{5}{|c|}{ Black Bedouin } \\
\hline CSRD247 & 9 & 0.839 & 0.817 & 26 & 0.330 \\
\hline OARAE54 & 12 & 0.857 & 0.860 & 22 & 0.522 \\
\hline ILSTS005 & 5 & 0.821 & 0.689 & 12 & 0.385 \\
\hline McM527 & 10 & 0.893 & 0.849 & 12 & 0.476 \\
\hline \multirow[t]{2}{*}{ Mean } & 9 & 0.853 & 0.804 & 20 & 0.415 \\
\hline & \multicolumn{5}{|c|}{ Damascus } \\
\hline CSRD247 & 9 & 0.773 & 0.817 & 24 & 0.310 \\
\hline OARAE54 & 8 & 0.591 & 0.836 & 22 & 0.320 \\
\hline ILSTS005 & 5 & 0.545 & 0.659 & 12 & 0.455 \\
\hline McM527 & 7 & 0.909 & 0.819 & 20 & 0.368 \\
\hline Mean & 7.25 & 0.705 & 0.783 & 19.5 & 0.363 \\
\hline Overall Mean & 8.17 & 0.761 & 0.779 & 19.67 & 0.394 \\
\hline
\end{tabular}

The allele frequency of each locus was plotted to describe the genetic variation within and between populations (Figure 2). The described alleles and their frequencies in the four loci studied for each flock are presented in Figure 2. The allele frequency profile, including allele frequencies and sizes, showed a high number of microsatellite alleles and a wide range of allele sizes for each locus in the populations studied. Furthermore, a specific profile of allele frequencies at each locus was observed, reflecting specific distributions of allele frequencies and sizes (Figure 2). Such profiles, however, do not usually reflect a normal distribution as would be expected and thus could be used to predict the level of the genetic variation and genetic differentiation within and between populations. In detail, the microsatellite loci differed considerably in allele frequency in the three flocks, locus to locus and population to population (Figure 2). Again, in the three populations, the profile of allele frequencies appeared to be far from binomial distribution, i.e., bell shape, except for ILSTS005 in which allele 180 was the most frequent. In addition, there were some similar observations, where the most frequent allele of CSRD247 was 218 and 154 for McM527, whereas the most common in OARAE54 was 120 in the Ardi and Black Bedouin populations and 134 in the Damascus goat population. In general, the majority of alleles were found in all three populations, except the alleles with low frequencies, i.e., private alleles (Figure 2). However, the comparisons between three flocks showed that some alleles were not commonly shared between them. These were 220 (9\%; CSRD247), 140 (2\%; OARAE54) and 186 (4.5\%; ILSTS005) in the Damascus goat population and $224(2.7 \%)$ in the Black Bedouin goat population. A possible inference could be geographical location, different selection forces, and non-common ancestor. Goat breed-specific alleles were previously observed at different loci for different populations with low frequency. For example Bolormaa et al. (2008) reported population-specific alleles (private alleles) for Australian and Mongolian populations. On the other hand, it is notable that alleles of extreme size in all populations and loci occur at very low frequencies. Similar observations were reported for Asian (Barker et al., 2001) and Swiss (Glowatzki-Mullis et al., 2008) goat breeds. This may indicate that the alleles did not get an advantage either due to random or selective forces. There are little differences in allele frequency profile between populations. 


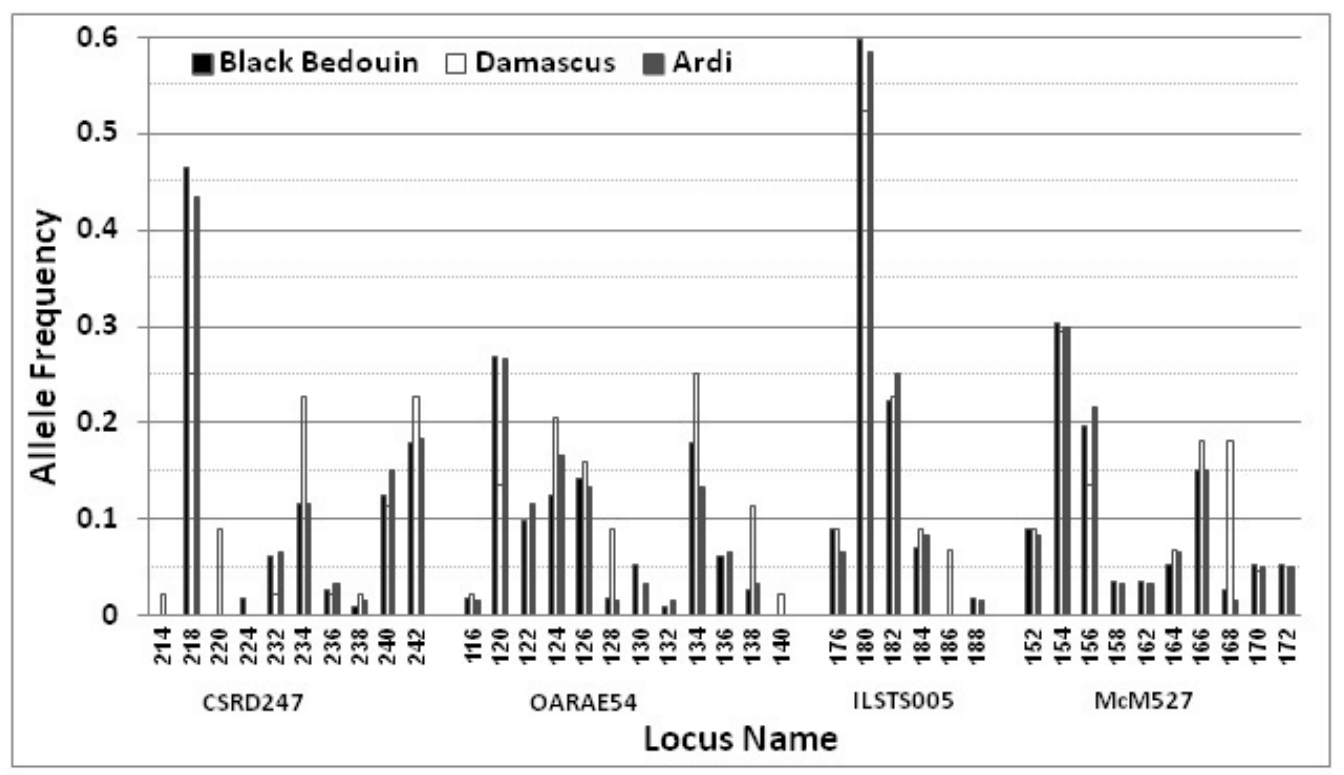

Figure 2. Allelic frequencies of the four microsatellites loci in the Ardi, Black Bedouin and Damascus goats.

The observed heterozygosity $\left(H_{\mathrm{O}}\right)$ and $\left(H_{\mathrm{E}}\right)$, commonly used measures of genetic diversity at a single locus, are shown in Table 1 . Average $\left(H_{\mathrm{O}}\right)$ and $\left(H_{\mathrm{E}}\right)$ ranged from 0.545 (ILSTS005) to 0.909 (McM527) in Damascus goats and to 0.588 (ILSTS005) in Ardi goats and 0.860 (OARAE54) in Black Bedouin goats. Black Bedouin goats showed the highest average gene diversity $\left(H_{\mathrm{E}}=0.804\right)$, while Ardi goats showed the lowest gene diversity $\left(H_{\mathrm{E}}=0.750\right)$ (Table 1). At most loci, $H_{\mathrm{O}}$ was lower than $H_{\mathrm{E}}$, except McM527 in which $H_{\mathrm{O}}=0.909$ and $H_{\mathrm{E}}$ $=0.819$. In relation, the number of alleles at the locus in Damascus goats was 7.25, whereas it was 8.25 and 9 in Ardi and Black Bedouin goats, respectively. The expected heterozygosities at each locus were $0.791,0.858,0.634$, and 0.834 for CSRD247, OARAE54, ILSTS005, and McM527, respectively. ILSTS005 showed the lowest $H_{\mathrm{O}}$ and $H_{\mathrm{E}}$ in all goat populations, whereas OARAE54 showed the highest $H_{\mathrm{E}}$ value. A similar range of values was reported by others (Visser et al., 2004; Takahashi et al., 2008; Serrano et al., 2009; Garrine et al., 2010). In a previous study of 14 microsatellite markers genotyped in Ardi goats, the expected heterozygozity was 0.675 (Aljumaah et al., 2012). In worldwide corresponding studies, the expected heterozygosities of world goat breeds varied from 0.16 in Mehsana and Sirohi breeds (Dixit et al., 2009) to 0.93 in the Vendi breed (Salles et al., 2011). Even though estimates of $H_{\mathrm{E}}$ and $H_{\mathrm{O}}$ were at only four loci, which is a limited number, they provided high and close estimates compared to those of similar studies. These results were expected for microsatellite loci, which demonstrated high polymorphism in all species studied so far, even with a small number of microsatellite markers. Furthermore, the markers studied were rich in the number of alleles, which as a consequence reflected the well-known relationship between high number of alleles per microsatellite locus and high heterozygosity estimates found in this study. Overall results indicated that the most genetically variable population was the Damascus goats, which had higher $H_{\mathrm{E}}$. This might have been due to various factors such as management and breeding 
practices under which the selection of each population took place. It is important to mention that, in this study, all loci studied showed significant deviation from HWE.

On the other hand, $G-W$ statistics showed the highest value (0.415) for Black Bedouin goats, a lower value (0.405) for Ardi goats and the lowest value (0.363) for Damascus goat. Whenever $G-W$ is low in a population, it is expected that the population is sensitive to bottleneck (Garza and Williamson, 2001). In other words, the $G-W$ statistic is supposed to be very small in a population having been through a bottleneck and close to one in stationary populations. Therefore, the Damascus goat population was subjected to a bottleneck (Table 1). This may be because the number of alleles was more reduced than the allele range, and as a consequence the distribution of allele length showed a wider range of base pair positions (Table 1).

\section{Genetic variation between populations}

AMOVA revealed the level of variation within and between populations. AMOVA revealed that the percentage of variation between populations was $1.49 \%$ and within populations, $98.51 \%$. Variance components among population were highly significant for all the loci studied, indicating 97.68, 98.05, 99.345, and 99.15\% for CSRD247, OARAE54, ILSTS005, and McM527, respectively. On the other hand, CSRD247 and OARAE54 contributed 2.32 and $1.94 \%$ of the variability within populations, respectively, and ILSTSO05 and McM527 showed the lowest variability of 0.66 and $0.85 \%$, respectively. Table 2 shows population average pairwise differences $\left(F_{\mathrm{ST}}\right)$ based on distance method of number of different alleles. The above diagonal estimates represent average pairwise differences between populations, while those below diagonal represent corrected average pairwise differences. $F_{\mathrm{ST}}$ values for each pair of populations varied from 0.004 to 0.069 . The $F_{\mathrm{ST}}$ values showed more differentiation between the Damascus and Ardi goats $\left(F_{\mathrm{ST}}=0.022-0.069\right)$ compared to differentiation between pairs of Ardi and Black Bedouin $\left(F_{\mathrm{ST}}=0.004-0.010\right)$ (Table 2). The pairwaise differences between Black Bedouin and Damascus goats ranged from 0.020 to 0.063 . Overall results indicate the evolutionary distinction of Damascus goats as an external group.

\begin{tabular}{|c|c|c|c|}
\hline & Ardi & Black Bedouin & Damascus \\
\hline Ardi & - & 0.004 & 0.022 \\
\hline Black Bedouin & 0.010 & - & 0.020 \\
\hline Damascus & 0.069 & 0.063 & - \\
\hline
\end{tabular}

\section{Genetic population differentiation and structure}

Another way to describe the genetic differentiation of the goat populations studied is considering genetic distances. Figure 3 shows population average pairwise difference between populations and within population and Nei's genetic distances between populations. The average genetic distance values across all loci was 0.060 , indicating that $6.0 \%$ of total genetic variation corresponded to differences between populations, whereas $94.0 \%$ was explained by 
difference between individuals within all populations. The within population indices (based on the stepwise mutation model) across loci was 3.10 (Figure 3). Mean pairwise comparisons between breeds showed that values were 3.12-3.22, a little higher than within population values. These results indicated that the amount of variation between Ardi and Damascus was around 3.1, while it was around 3.22 between Black Bedouin and Damascus. Genetic distances were estimated as pairwise genetic distances using the genetic distance method described by Nei (1987). As expected on the basis of the pairwise genetic difference estimates described in Figure 3, the genetic distance between Ardi and Black Bedouin goats was relatively short, i.e., 0.01037 . Figure 3 reveals a very small degree of differentiation between populations. The notable difference was between Ardi and Damascus of 0.06885 and between Black Mountain and Damascus of 0.06312. Note that an exact test for population differentiation for all pairs of breeds across all loci showed that all breeds were significantly $(\mathrm{P}<0.001)$ different from each other.

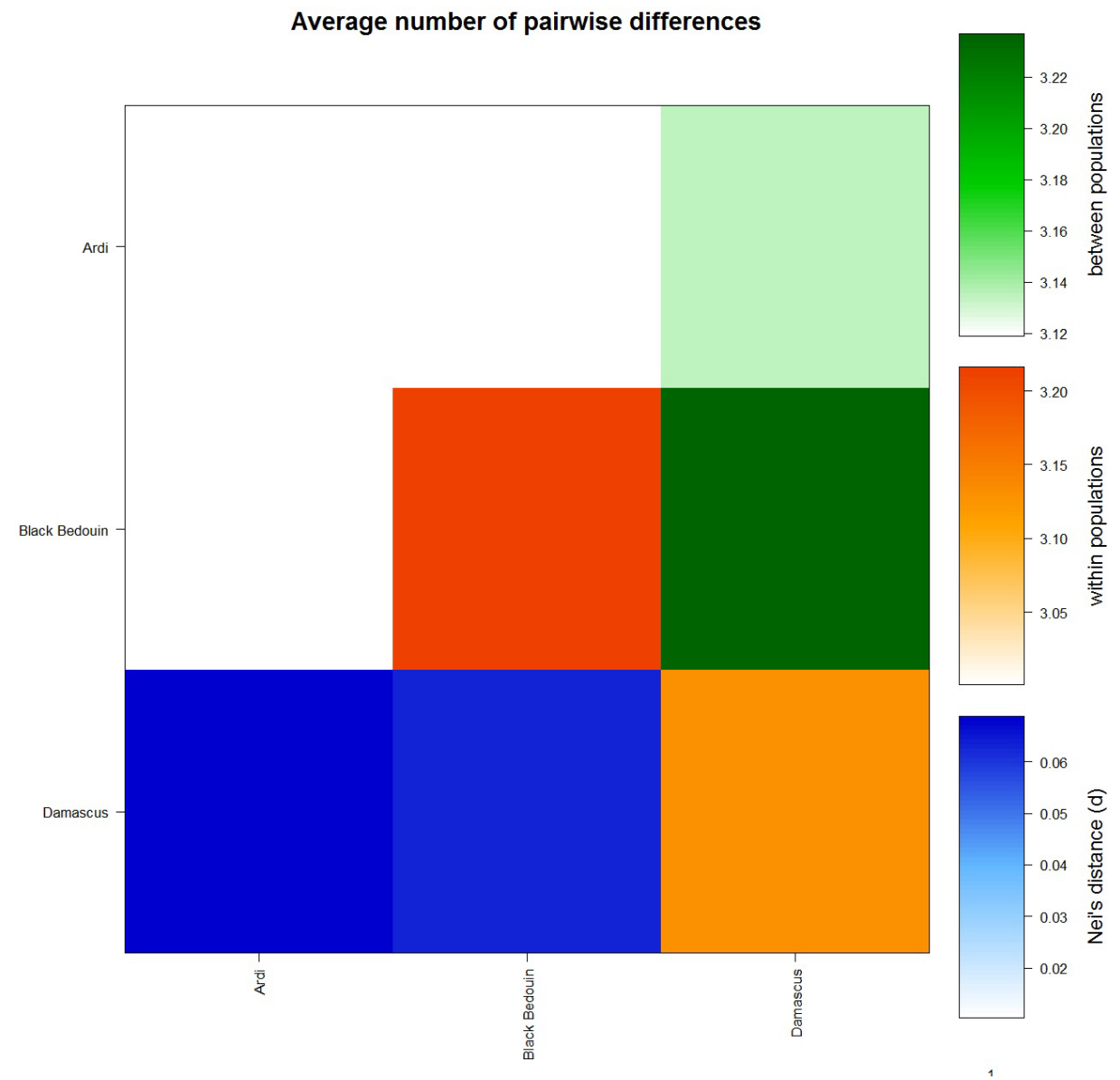

Figure 3. Population average pairwise differences between populations, within population and corrected average pairwise genetic distances between the three populations studied. 
Goat population genetic structure was determined using the STRUCTURE software with $\mathrm{K}=2$ to $\mathrm{K}=4$, assuming admixture and correlated allele frequencies model. The purpose was to test whether each goat individual had a mixed ancestry by assuming that some fraction of genome inherited from ancestors in the population for probable number of $\mathrm{K}$. The likelihood values of the bootstrap samples were for choosing the optimal $\mathrm{K}$ value leading to the most reliable result membership coefficients to two and three clusters $(\mathrm{K}=2 ;-1,265)$ and $\mathrm{K}=3 ;-1,300$ ). It stated that there would be most probably two populations accounted as ancestral populations for current populations studied. This resulting case indicates that number of population groups is less than the predefined one. As a consequence, individuals are subdivided into a group of two to which they historically belong before they were defined as the three current defined populations (Figure 4). As a consequence, the graphic representation in Figure 4 shows that $53 \%$ of the first group come from individuals of both Ardi and Black Bedouin, whereas the rest (47\%) from the Damascus goats. It is otherwise in the second group in which $\sim 60 \%$ were Damascus goats (Figure 4 ). On the other hand, admixture between Black Bedouin and Ardi goats was evident when the number of populations considered was three $(\mathrm{K}=3)$, the real case in this study. The major overall contribution in the first two groups was by Ardi of $\sim 38 \%$, whereas $41.5 \%$ of Damascus goats in the third group (Figure 4 ). The individual admixture proportions showed that one cluster corresponded to both Ardi and Black Bedouin, which could not be separated because of low genetic differentiation and the other cluster to the Damascus goat. There is strong evidence of admixture between the majority of Ardi and Black Bedouin goat individuals. This result is probably due to migration or shared ancestry between the three populations studied. On the other hand, the average admixture proportion of Ardi and Damascus goat individuals was low (20\%), indicating non-admixed individuals.

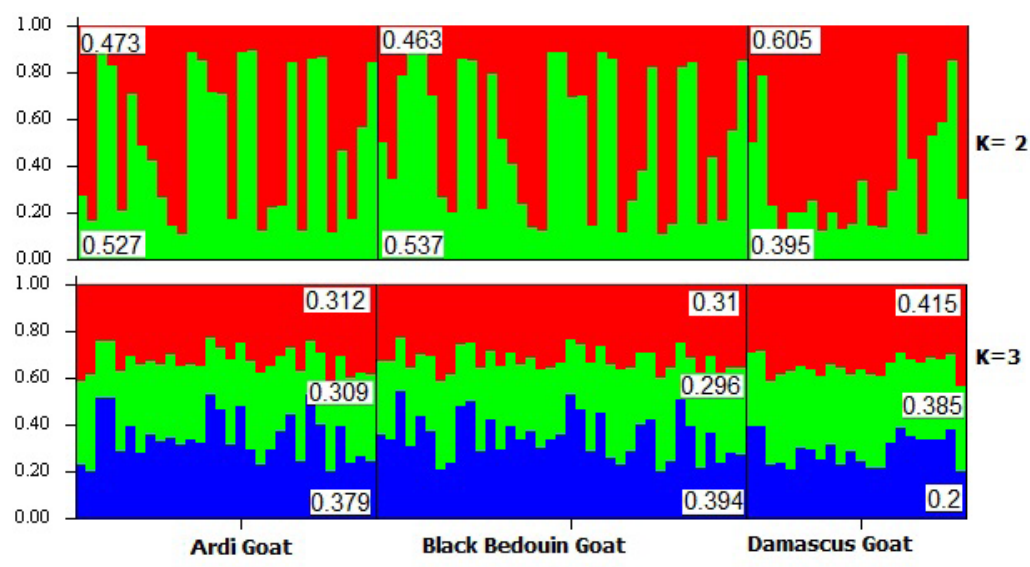

Figure 4. Estimated population structure for each individual represented by a single vertical line broken into $\mathrm{K}$ colored segments, with lengths proportional to each predefined populations of $\mathrm{K}$ from 2 to 5 .

Figure 5 shows how evolutionary relationships of the three populations were inferred using the neighbor-joining method (Saitou and Nei, 1987). The optimal tree with the sum of branch length equal to 0.071 is shown. The tree is drawn to scale, with branch lengths in the same units as those of the evolutionary distances used to infer the phylogenetic tree (Figure 5). 
The neighbor-joining tree revealed two different clusters (Figure 5). The first cluster consisted of the Ardi and Black Bedouin goat breeds, and the second cluster consisted of the Damascus goat breed alone. The resulting clusters reflected the outcomes from $F_{\mathrm{ST}}$ estimates (Table 2). There is a long evolutionary distance separating the Ardi and Black Bedouin goats as one similar group from the Damascus goat population. Overall, the clustering of populations in consensus neighbor-joining trees followed the previously mentioned relationships between groups (Figures 3 and 4). The first cluster of Ardi and Black Bedouin populations consistently appeared in a clade distant from Damascus goats. These results are in accordance with the $F_{\text {ST }}$ data showing that Ardi and Black Bedouin goats belong to the same evolutionary ancestor. Furthermore, they are from the same evolutionary group and less related to Damascus goats. The results also agreed with historical and geographical information and origins of the three populations. In fact, these findings are in agreement with geographical partitioning of goats in Europe and the Middle East, where two Saudi goat breeds (Beeshi and Najarani) were considered along with breeds from Europe and the Middle East (Cañón et al., 2006). The proved hypothesis was that goat migrated from Arabian Peninsula countries through Middle East countries towards Eastern and Western Europe. It would then be expected that the closer goat populations are geographically, the closer they are genetically.

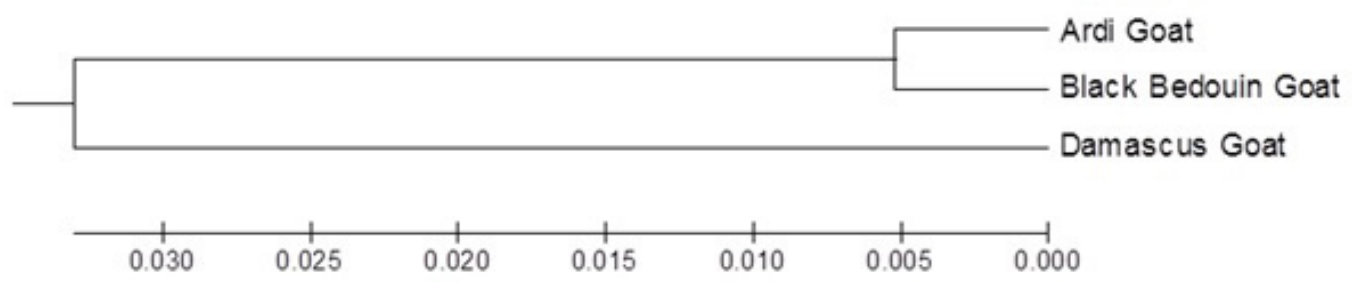

Figure 5. Neighbor-joining dendrogram showing the genetic relationship among the goat populations studied. The numbers below each branch indicate the branch length in units of genetic distance.

In general, the overall results are similar to previous findings. For example, differentiation was found between three native breeds of Jordanian goats from Damascus goats that were locally reared, on the basis of morphological traits (Zaitoun et al., 2005) and recently DNA sequence markers (Al-Atiyat et al., 2012). Furthermore, the present study provides the first phylogenetic reconstruction of common native breeds in KSA, Jordan, and Syria. This reconstruction reflected to some extent some expectations about the evolutionary history of the shared genes that would be accumulated in each population and form their morphological, production and heat tolerance traits. Another scope of the results being of value is that they may shed light on the traits of interest of closely related populations to understand the mechanisms of evolution considering the interaction with their own habitat on the one hand. On the other hand, considering closer phylogenic populations for introgression and crossbreeding programs will hopefully be of benefit.

\section{CONCLUSION}

The three populations studied expressed a high level of genetic variation revealed by high $H_{\mathrm{E}}$ and $H_{\mathrm{O}}$, the number of alleles per locus with significant deviation from HWE. The 
latter showed specific allele frequency profiles far away from the normal distribution for most loci studied. Furthermore, allele frequency profiles were used to explain the level of genetic differentiation between the populations. The results based on F-statistics estimates clarified the differentiation between and within populations, indicating that $6.0 \%$ of total genetic variation corresponded to differences between populations, whereas $94.0 \%$ was explained by difference between individuals within all populations. The average within population indices across the loci was 3.10-fold. Mean pairwise comparisons between breeds showed that values were 3.12-3.22, a little higher than within population values. These results indicate that the amount of variation between Ardi and Damascus is less than that between Black Bedouin and Damascus. In addition, there is strong evidence of admixture between the majority of Ardi and Black Bedouin goat individuals, indicating possible migration or shared ancestry. On the other hand, the average admixture proportion of Damascus goat individuals was low indicating few admixed individuals. Genetic distance between Ardi and Black Bedouin goats was the shortest, whereas it was longest between Ardi and Damascus goats. Phylogenetic relationship clearly revealed the expected degree of differentiation in the three populations. Overall, the present study sheds new light on genetic differentiation and phylogenetic relationships of common native goats in core countries of the Middle East. From a genetic conservation point of view, it is recommended to maintain the biodiversity of these distinct populations in case genetic migration of genetic resources and genetic conservation are absent.

\section{ACKNOWLEDGMENTS}

Research supported by the Deanship of Scientific Research at King Saud University (\#RGP-VPP-042).

\section{REFERENCES}

Agha SH, Pilla F, Galal S, Shaat I, et al. (2008). Genetic diversity in Egyptian and Italian goat breeds measured with microsatellite polymorphism. J. Anim. Breed. Genet. 125: 194-200.

Ajmone-Marsan P (2010). A global view of livestock biodiversity and conservation - GLOBALDIV. Anim. Genet. 41 (Suppl 1): 1-5.

Al-Atiyat RM, Salameh NM and Tabbaa MJ (2012). Phylogeny and evolutionary analysis of goat breeds in Jordan based on DNA sequencing. Pak. J. Biol. Sci. 15: 850-853.

Al-Tamimi HJ (2005). Effects of solar radiation on thermophysiological and growth parameters of indigenous Black Bedwin goat kids in southern Jordan. J. Biolog. Sci. 5: 724-728.

Al-Tamimi HJ, Obeidat BS, Abdullah AY and Al-Atiyat RM (2013). Disproportionate thermophysiological strain between intensively- and extensively-managed goats during summer. Small Rum. Res. 109: 1-8.

Alamer M (2006). Physiological responses of Saudi Arabia indigenous goats to water deprivation. Small Rum. Res. 63: 100-109.

Aljumaah RS, Musthafa MM, Al-Shaikh MA, Badri OM, et al. (2012). Genetic diversity of Ardi goat based on microsatellite analysis. Afri. J. Biotech. 11: 16539-16554.

Alpha Innotech Corp. (2010). AlphaSpec Spectrophotometer. Available at [http://www.photonics.com/Article. aspx?AID=33348]. Accessed February 6, 2012.

Barker JSF, Tan SG, Moore SS, Mukherjee TK, et al. (2001). Genetic variation within and relationships among populations of Asian goats (Capra hircus). J. Anim. Breed. Genet. 118: 213-233.

Bolormaa S, Ruvinsky A, Walkden-Brown S and Van der Werf J (2008). Genetic relationships among Australian and Mongolian fleece-bearing goats. Asian-Aust. J. Anim. Sci. 21: 1535-1543.

Cañón J, Garcia D, Garcia-Atance MA, Obexer-Ruff G, et al. (2006). Geographical partitioning of goat diversity in Europe and the Middle East. Anim. Genet. 37: 327-334. 
Devendra C and McLeroy GB (1987). Goat and Sheep Production in the Tropics. Longman Scientific and Technical Publishers, Singapore.

Dixit SP, Verma NK, Aggarwal RAK, Kumar S, et al. (2009). Genetic structure and differentiation of three Indian goat breeds. Asian-Aust. J. Anim. Sci. 22: 1234-1240.

Epstein H (1946). The Hejaz Dwarf goat. J. Heredity 37: 345-352.

Excoffier L and Lischer HE (2010). Arlequin suite ver 3.5: a new series of programs to perform population genetics analyses under Linux and Windows. Mol. Ecol. Resour. 10: 564-567.

FAO (2011). Molecular Genetic Characterization of Animal Genetic Resources. Food and Agriculture Organization. Animal Production and Health Guidelines, Rome.

Galal S (2005). Biodiversity in goats. Small Rum. Res. 60: 75-81.

Garrine C, Kotze A, Els H and Grobler J (2010). Genetic characterization of the indigenous Landim and Pafuri goat breeds from Mozambique. Afric. J. Agri. Res. 5: 3130-3137.

Garza JC and Williamson EG (2001). Detection of reduction in population size using data from microsatellite loci. Mol. Ecol. 10: 305-318.

Glowatzki-Mullis ML, Muntwyler J, Bäumle E and Gaillard C (2008). Genetic diversity measures of Swiss goat breeds as decision-making support for conservation policy. Small Rum. Res. 74: 202-211.

Karaca M, Karaca F, Patel C and Emara M (1999). Preliminary Analysis of Microsatellite Loci in Commercial Broiler Chickens. Proceedings of the Plant and Animal Genome 7th Conference, January 17-21, San Diego.

Mason IL (1984). Goat. In: Evolution of domesticated Animals (Mason IL, ed.). Longman, London, 85-99.

Nei M (1987). Molecular Evolutionary Genetics. Columbia University Press, New York.

OMEGA Bio-Tek (2010). E.Z.N.A ${ }^{\circledR}$ MicroElute Genomic DNA extraction Kit OMEGA. Available at [www.omegabiotek. com]. Accessed November 12, 2011.

Pereira F, Queiros S, Gusmao L, Nijman IJ, et al. (2009). Tracing the history of goat pastoralism: new clues from mitochondrial and Y chromosome DNA in North Africa. Mol. Biol. Evol. 26: 2765-2773.

Piper L and Ruvinsky A (1997). The Genetics of Sheep. CAB International, New York.

Pritchard JK, Stephens M and Donnelly P (2000). Inference of population structure using multilocus genotype data. Genetics 155: 945-959.

Saitou N and Nei M (1987). The neighbor-joining method: a new method for reconstructing phylogenetic trees. Mol. Biol. Evol. 4: 406-425.

Salles PA, Santos SC, Rondina D and Weller M (2011). Genetic variability of six indigenous goat breeds using major histocompatibility complex-associated microsatellite markers. J. Vet. Sci. 12: 127-132.

Serrano M, Calvo JH, Martinez M, Marcos-Carcavilla A, et al. (2009). Microsatellite based genetic diversity and population structure of the endangered Spanish Guadarrama goat breed. BMC Genet. 10: 61.

Silanikove N (1986). Feed utilization, energy and nitrogen balance in the desert black Bedouin goat. World Rev. Anim. Prod. 22: 93-96.

Tabbaa M and Al-Atiyat R (2009). Breeding objectives, selection criteria and factors influencing them for goat breeding in Jordan. Small Rum. Res. 84: 8-15.

Takahashi H, Nyamsamba D, Mandakh B, Zagdsuren Y, et al. (2008). Genetic structure of Mongolian goat populations using microsatellite loci analysis. Asian-Aust. J Anim. Sci. 21: 947-953.

Tamura K, Peterson D, Peterson N, Stecher G, et al. (2011). MEGA5: molecular evolutionary genetics analysis using maximum likelihood, evolutionary distance, and maximum parsimony methods. Mol. Biol. Evol. 28: 2731-2739.

Visser C, Hefer C, van Marle-Köster E and Kotze A (2004). Genetic variation of three commercial and three indigenous goat populations in South Africa. South Afri. J. Anim. Sci. 34: 24.

Zaitoun IS, Tabbaa MJ and Bdour S (2005). Differentiation of native goat breeds of Jordan on the basis of morphostructural characteristics. Small Rum. Res. 56: 173-182.

Zeder MA and Hesse B (2000). The initial domestication of goats (Capra hircus) in the Zagros Mountains 10,000 years ago. Science 287: 2254-2257.

Zeuner FE (1963). A History of Domesticated Animals. Hutchinson, London. 